\title{
Commentary
}

\section{Novel stretching and strength-building exercise recommendations for computer-based workers during the COVID-19 quarantine}

\author{
Ardalan Shariat ${ }^{\mathrm{a}}$, Shima Ghannadi ${ }^{\mathrm{a}, *}$, Albert Thomas Anastasio ${ }^{\mathrm{b}}$, Mitch Rostad \\ and Joshua A. Cleland ${ }^{\mathrm{d}}$ \\ ${ }^{a}$ Sports Medicine Research Center, Neuroscience Institute, Tehran University of Medical Sciences, Tehran, Iran \\ ${ }^{\mathrm{b}}$ Department of Orthopaedic Surgery, Duke University, Durham, NC, USA \\ ${ }^{\mathrm{c}}$ Organ Preservation Alliance, Berkeley, CA, USA \\ ${ }^{\mathrm{d}}$ Therapy Program, Department of Public Health and Community Medicine, Tufts University School of Medicine, \\ Boston, MA, USA
}

Received 6 June 2020

Accepted 9 June 2020

\begin{abstract}
.
BACKGROUND: Prolonged home stays due to the COVID-19 quarantine can increase the use of computers and other technologies that may lead to significant reduction in activity, contributing to musculoskeletal problems, anxiety and depression.

OBJECTIVE: The aim of this study was to develop a novel multicomponent exercise program for individuals who work with computers during the COVID-19 quarantine.

METHODS: Researchers collaborating cross-institutionally and cross-nationally performed a careful literature search for exercise and stretching regiments with particular attention to methodologies that can be applied during the lockdown in the wake of the COVID-19 pandemic. Methodologies were then compiled and truncated for ease of use for the computer-based office worker during the COVID-19 pandemic quarantine.

RESULTS: The resulting program is broken down into three categories: aerobic, strengthening and stretching components. Each component can then be further modified to meet the frequency, intensity, time and type (FITT) specifications for the participant.

CONCLUSIONS: We present a novel, evidence-based strategy for functional fitness for office workers who have remained home-bound during the COVID-19 pandemic quarantine. Further research should seek to validate the efficacy of the proposed protocol.
\end{abstract}

Keywords: Office, fitness, musculoskeletal pain, COVID-19, pandemic

\footnotetext{
*Address for correspondence: Dr. Shima Ghannadi, Sports Medicine Research Center, Neuroscience Institute, Tehran Uni-
}

versity of Medical Sciences, Tehran, Iran. Tel.: +989127147157; E-mail: sh_ghannadi90@yahoo.com. 


\section{Introduction}

COVID-19 was diagnosed in late 2019 in Wuhan, China, after assessment of multiple cases of acute respiratory infection and identification of a novel strain of coronavirus [1] The causative pathogen of this disease is a mutant and novel virus from the coronavirus family called SARS-CoV-2 (severe acute respiratory syndrome coronavirus 2), which has spread across the word in a few months [2]. The World Health Organization (WHO) sent out notifications on January 30, 2020 that the outbreak of COVID-19 disease is a global health emergency and announced on March 11 that the disease had reached pandemic levels $[3,4]$.

Based on the analysis of disease spread statistics, China has managed to reduce the number of daily infections [5]. Many epidemiologists believe that many successes in controlling the virus in China have been due to the swift action taken by the authorities to impose quarantine conditions on the vast majority of their people [6]. Therefore, major countries that have been particularly effected by COVID-19 (such as the USA, Germany, Iran, Spain, Italy, etc.) have adopted similar strategies and the WHO and the Ministry of Health have required home quarantine as a disease control mechanism $[7,8]$.

The onset of a sudden quarantine indicates a fundamental change in people's lifestyles. Although a quarantine period appears to be an effective strategy to stop the contagion, the lock-down may have significant effects on other aspects of the health of isolated patients. Travel restrictions and outdoor activities inevitably disrupt a person's daily activities. Therefore, such individuals are more likely to experience inadequate physical activity, increased immobility, anxiety and depression, which may pose significant health and well-being risks [9].

The world has been living with another pandemic for a number of years - physical inactivity that has been identified as one of the four leading contributors to premature mortality [10, 11]. It is established that inadequate physical activity is a major risk factor for cardiovascular disease, hypertension, diabetes and respiratory diseases, which are also risk factors for the COVID-19 [12-14]. In addition, following decreases in physical activity, the muscles (especially the muscles of the back) get weak and can become atrophied, which can cause musculoskeletal pain such as low back pain, neck pain or pain in the shoulder region [15-18].
In today's modern and industrialized world, many people utilize a laptop, personal computer or smartphone for a variety of purposes, including communication, entertainment, work, and other daily activities. It is reasonable to assume that usage of such devices is increasing due to home quarantine. In a previous study, Qin et al. acknowledged that during the quarantine period, the number of Chinese citizens with inadequate physical activity was more than twice the global prevalence, and their screen time was more than four hours per day [19]. This also implied that physical activity may be used as an effective way to decrease sedentary screen time, especially for young adults.

Studies show that physical exercise is an effective way to reduce the risk of development of cardiovascular diseases and death [13]. Exercise therapy is a known non-pharmacological treatment in developed and developing countries for people suffering from physical, physiological or psychological problems [20]. Exercise is not only effective on physical issues but can also improve physiological and psychological aspects of individuals at work and home.

Official measures that restrict people's movements in the presence of the coronavirus crisis do not necessarily mean that physical activity must be limited or that all forms of exercise must be eliminated entirely. There is a strong health reason to continue physical activity at home to stay healthy and maintain immune system function in the current unfavorable situation.

The home-based fitness regimens should be easy to do without the need for special equipment and come with clear instructions. Therefore, it is critically important to promote a healthy lifestyle by offering more suggestions and professional fitness guidance for people staying at home, especially those who are working with computers during the initial stages of the COVID-19 outbreak. Thus, publicly available, and evidence-based professional exercise and fitness health guidelines for computer-based worker in epidemic areas are indispensable.

The principle elements for a proper exercise program that is confined to the home environment are exercise modality, frequency of practice, volume and intensity. A multicomponent exercise program includes aerobic training, resistance training, and stretching components [21]. Thus, we describe these features in three main parts: aerobic training, resistance training and stretching training. Each component meets the frequency, intensity, time and type (FITT) recommendations for individuals with clinical conditions and for healthy individuals 
with special considerations. Even if an individual cannot meet the recommended targets, performing some exercise is beneficial, especially in inactive or deconditioned individuals, and, for this reason, should be encouraged except where there are safety concerns.

\section{Aerobic training}

Aerobic training promotes improvements in cardiorespiratory fitness, cardiometabolic biomarkers, and other fitness and health-related physiological variables, especially when including repeated bouts of exercise in several days per week. Musculoskeletal injuries are of concern to adults and may be reduced by including a warm-up (at least 5-10 minutes of light-to-moderate intensity cardiorespiratory and muscular endurance activities) and cool-down (at least 5-10 minutes of light-to-moderate intensity cardiorespiratory and muscular endurance activities), stretching exercises (at least $10 \mathrm{~min}$ of stretching exercises performed after the warm-up or cool-down phase), and gradual progression of volume and intensity $[22,23]$.

\subsection{Exercise frequency}

According to the American College of Sports Medicine (ACSM) and American Heart Association (AHA) physical activity recommendations, all healthy adults aged 18-65 year should do aerobic activity for a minimum 3-5 days/week with the frequency varying with the intensity of exercise [22-26]. Under the quarantine measures with reduction in day-to-day activity, these recommendations could be increased to include all days of the week with adaptation in volume and intensity.

\subsection{Exercise intensity}

The minimum threshold of intensity for benefit seems to vary depending on an individual's current cardiorespiratory fitness level and other factors such as age, health status, physiologic differences, genetics, habitual physical activity, and social and psychological factors [27-29]. Therefore, precisely defining an exact threshold to improve cardiorespiratory fitness may be difficult [28]. The guidelines suggest moderate intensity for most of the sessions and some amount of vigorous exercise per week. It is well-known that exercise at moderate intensity improves the immune system, but vigorous intensity may even inhibit it, especially in sedentary people. Thus, during quarantine times, moderate intensity (40-60\% heart rate reserve or O2R) and light (e.g., $30 \%-39 \%$ HRR or O2R) to moderate intensity aerobic exercise for deconditioned ones should be the ideal choice for people to enhance the protective role of exercise.

\subsection{Exercise time (duration)}

The guidelines recommend most adults are better to accumulate $30-60 \mathrm{~min}$ per day $(\geq 150 \mathrm{~min}$ per week) of moderate intensity exercise [23, 24] which in this particular quarantine situation could be increased to 200-400 minutes per week distributed among 5-7 days to compensate for the decrease in the normal daily physical activity levels. However, less than 20 min of exercise per day can be beneficial, especially in previously sedentary individuals. Additionally, participants can perform aerobic activity in intervals of 10 minutes to eventually total the 30 minutes minimum.

\subsection{Exercise type}

Regular, purposeful exercise that involves major muscle groups and is rhythmic and continuous is recommended. In and individual does not have access to large equipment or specific materials for training, the following options are available in any house: walking inside the house, jumping jacks, skipping rope, and stair climbing.

\section{Resistance training}

As noted previous, a sedentary lifestyle is associated with poor health outcomes [30] and increasing physical activity is associated with improvements in blood glucose control and HDL cholesterol with concomitant reduction in waist circumference and systolic blood pressure [31, 32]. A simple fitness plan, based on the fundamental movements of human life (overhead press, push, pull, squat/stand) can be used to develop functional health and improve immunological status [33]. Additionally, a common misconception is that strength training does not develop your cardiovascular system and provide the same benefits as strict aerobic training, or "cardio" When myocytes contract and fatigue, lactic acid is built up in the systemic circulation. This anaerobic 
Push:

Push-up on wall or counter

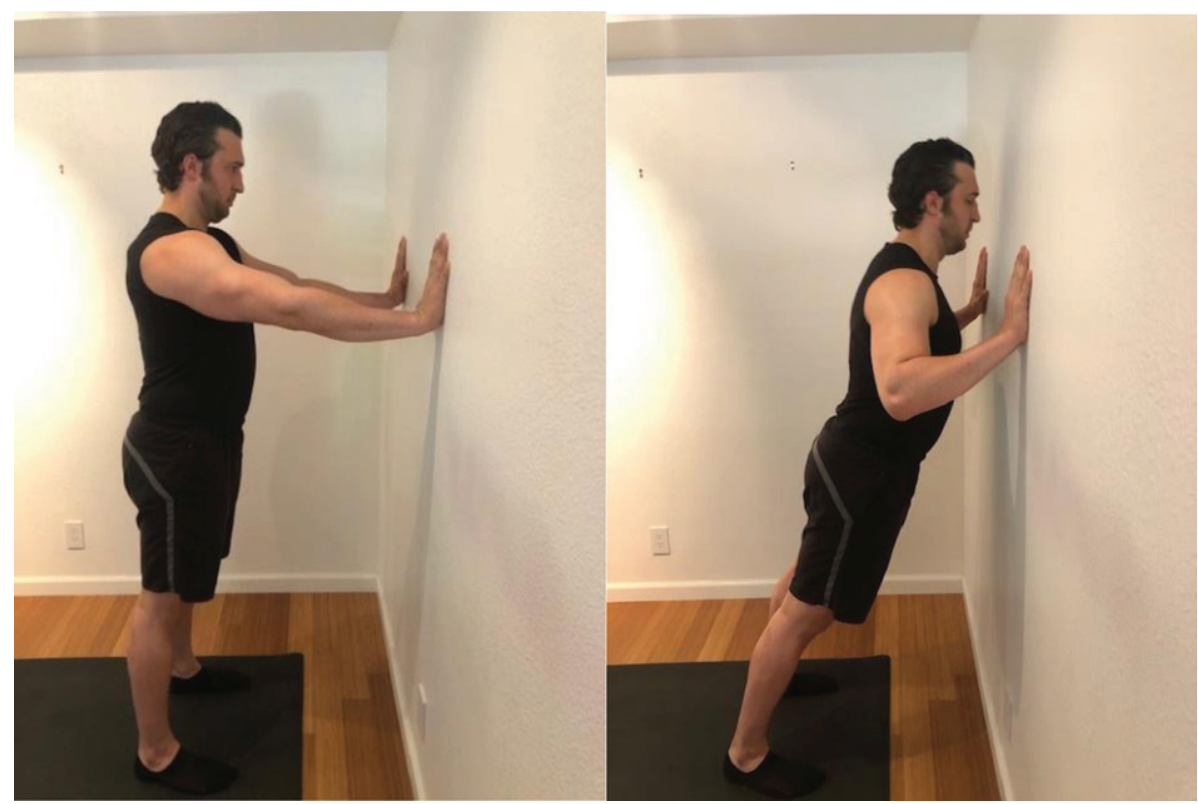

Standard push-up

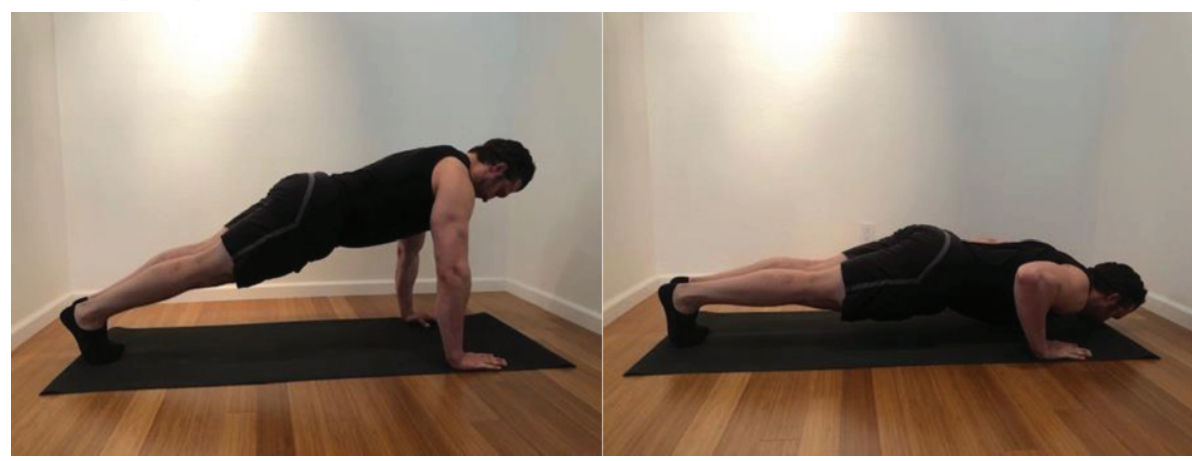

Decline push-up

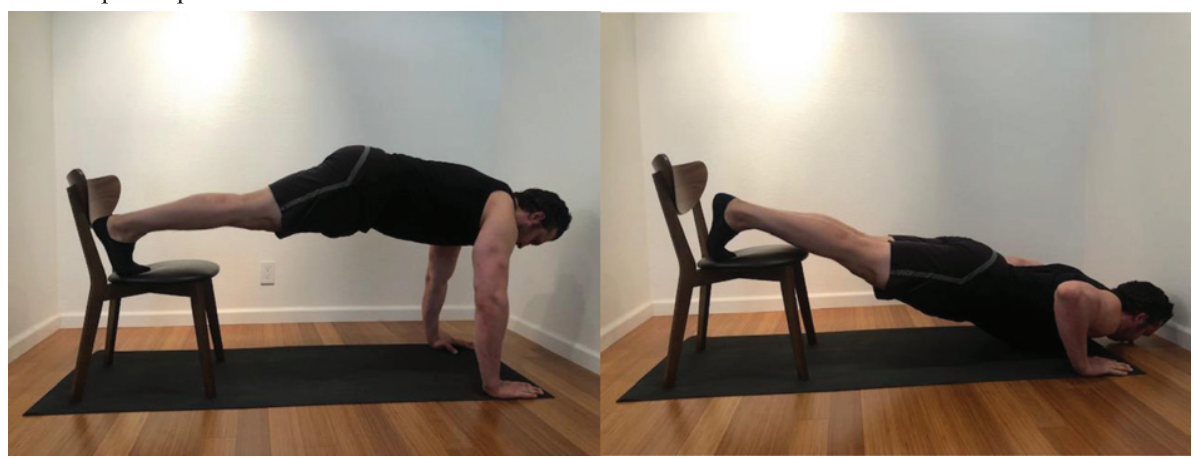




\section{Pull:}

Prone row (contract back and hold for 10/20/30 seconds per set)

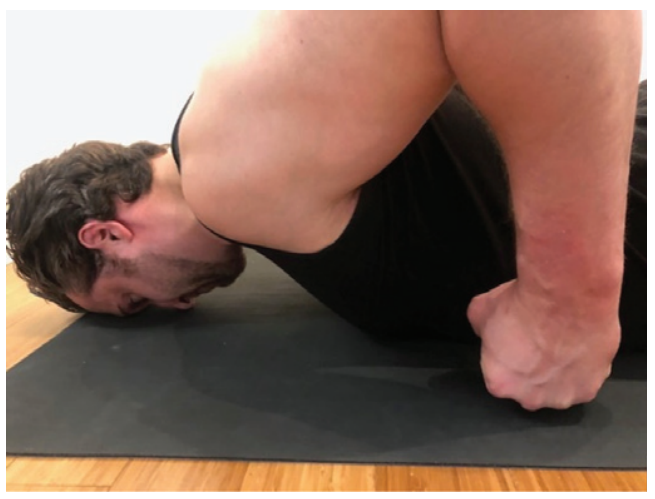

Double/single arm leaning doorframe row

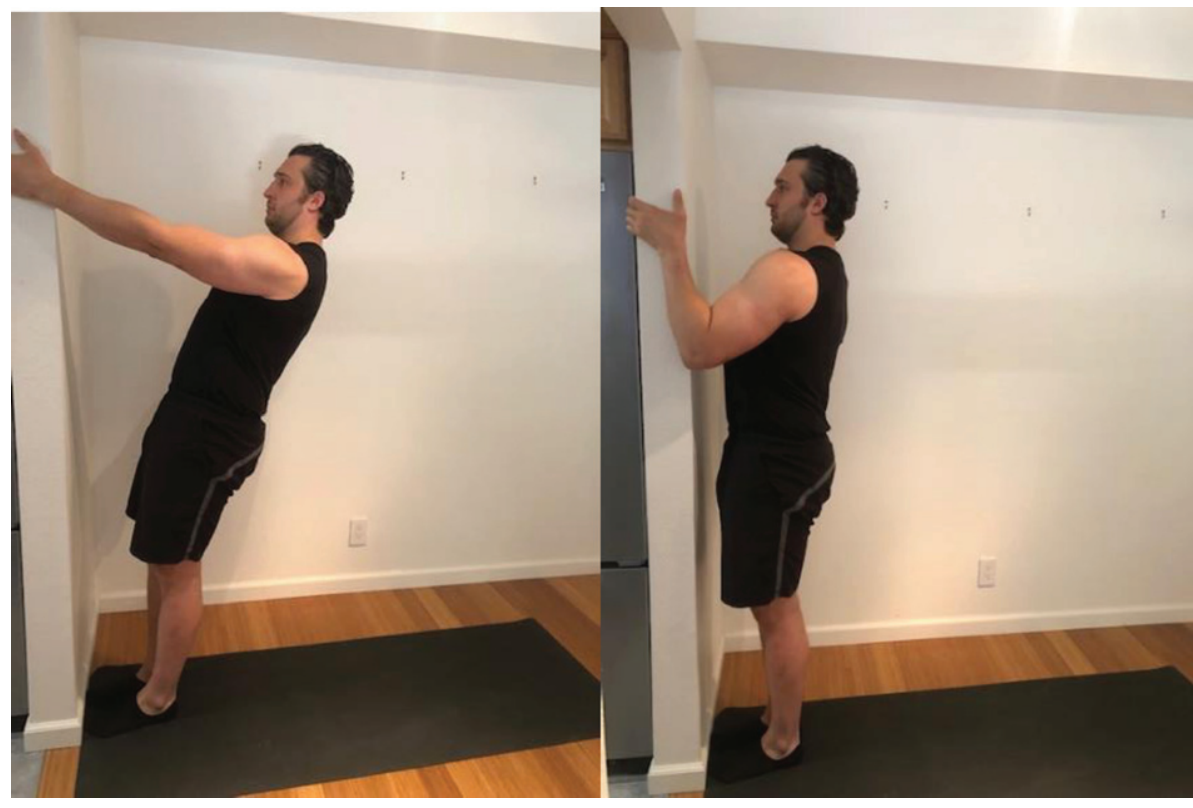

Double/single arm table/desk/chair row

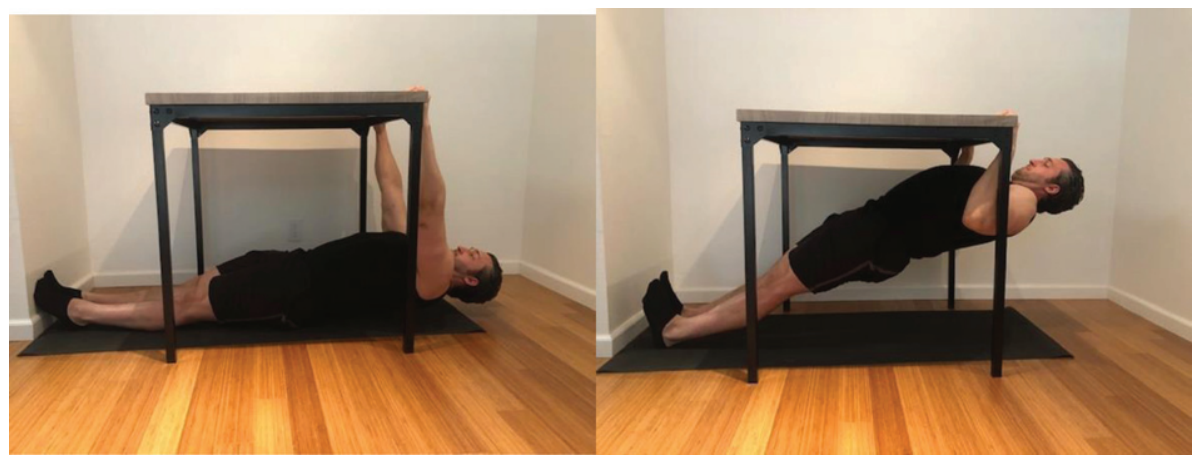




\section{Overhead Press:}

Floor overhead press

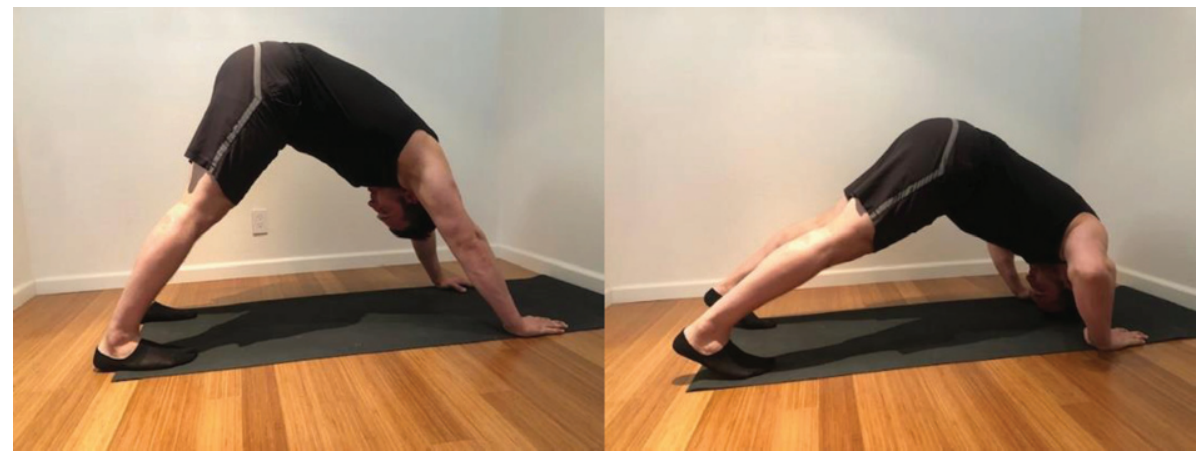

Elevated overhead press

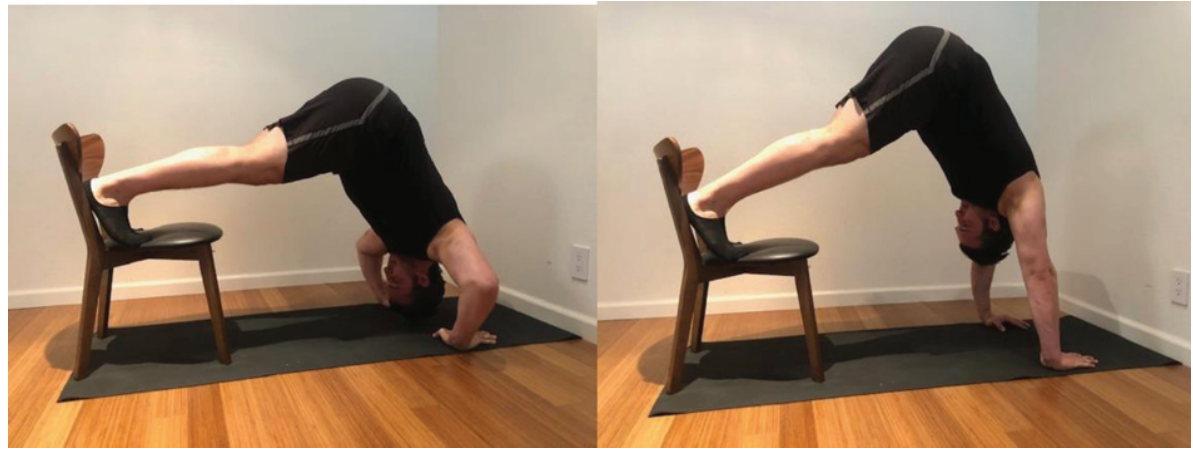

Handstand push-up

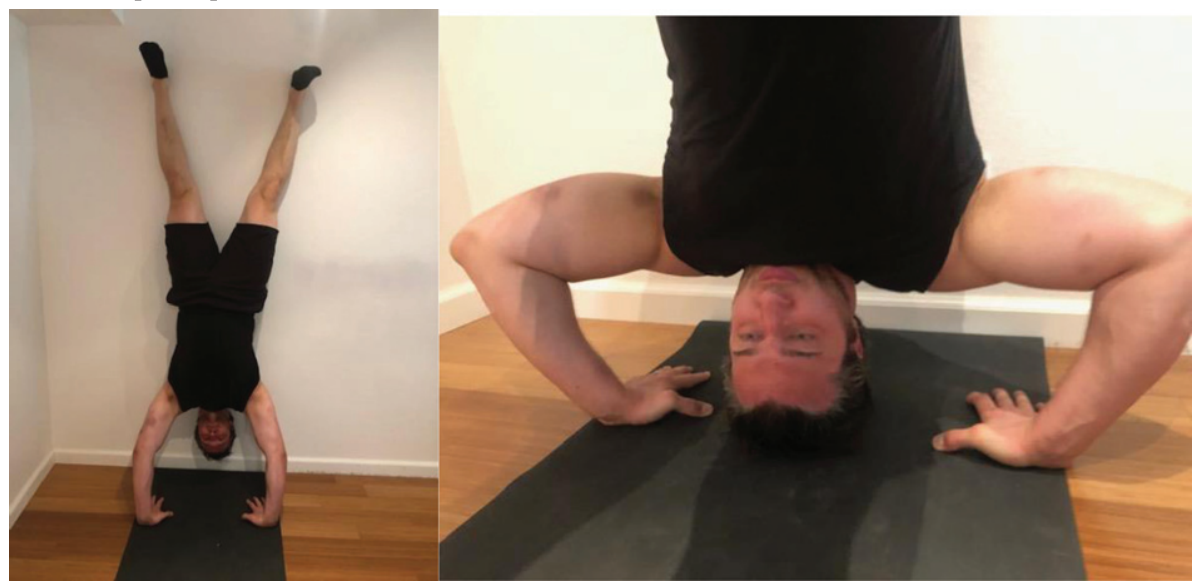


Squat/Stand:

Squat to chair

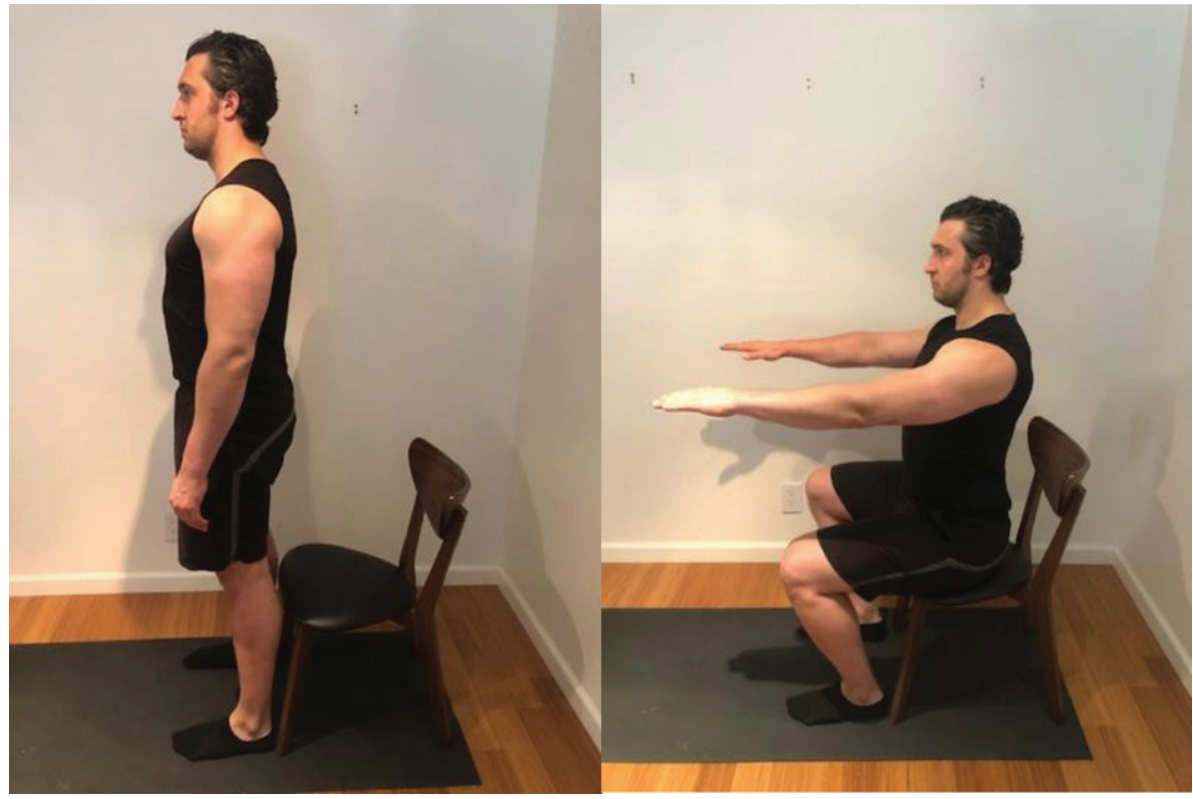

Elevated single leg squat

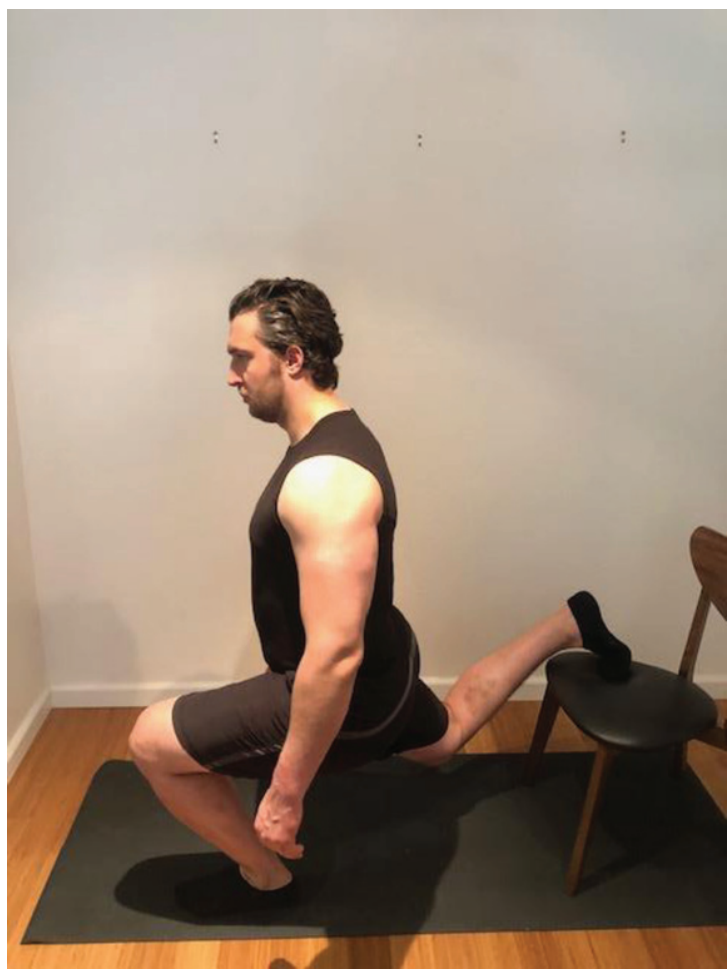




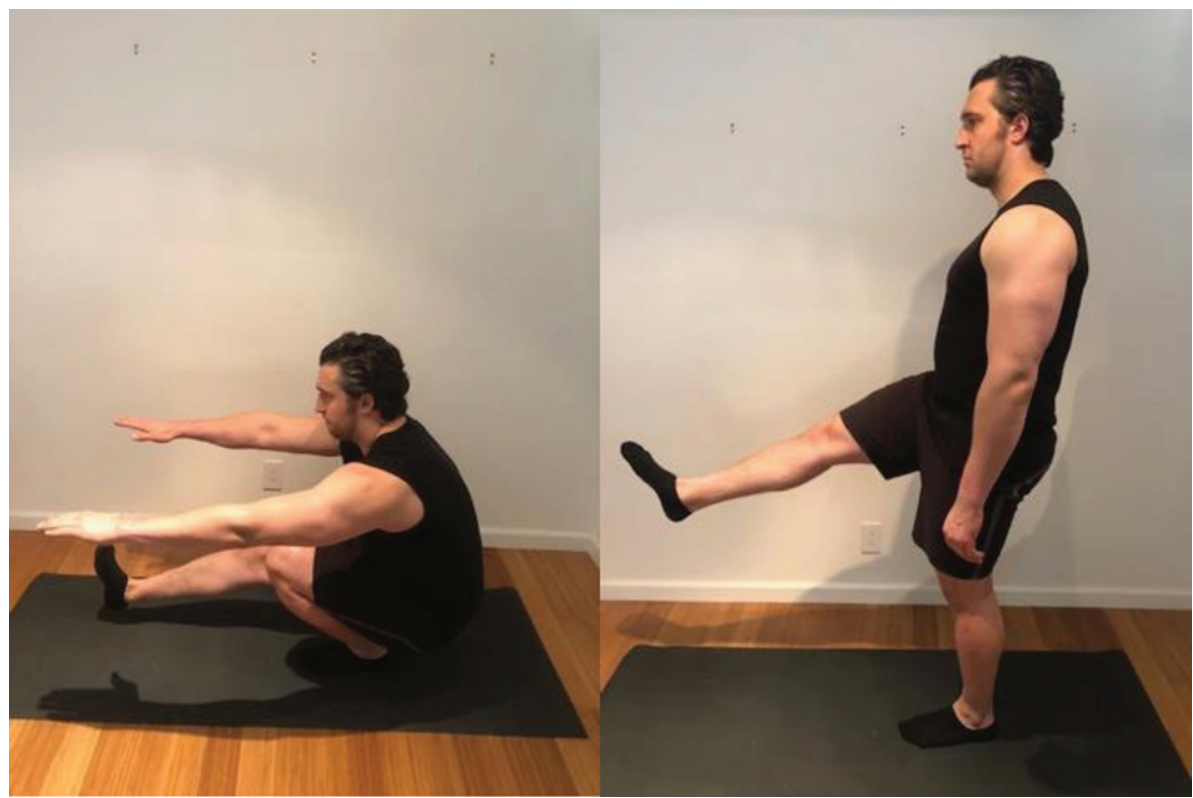

Core strength:

- *Perform positions in succession for 3-5 sets, rest 30 seconds to 1 minute between sets

Beginner: 10 seconds contracted, 10 second relaxed for 60 seconds per position

Advanced: 30 seconds-1 minute contracted in each successive position

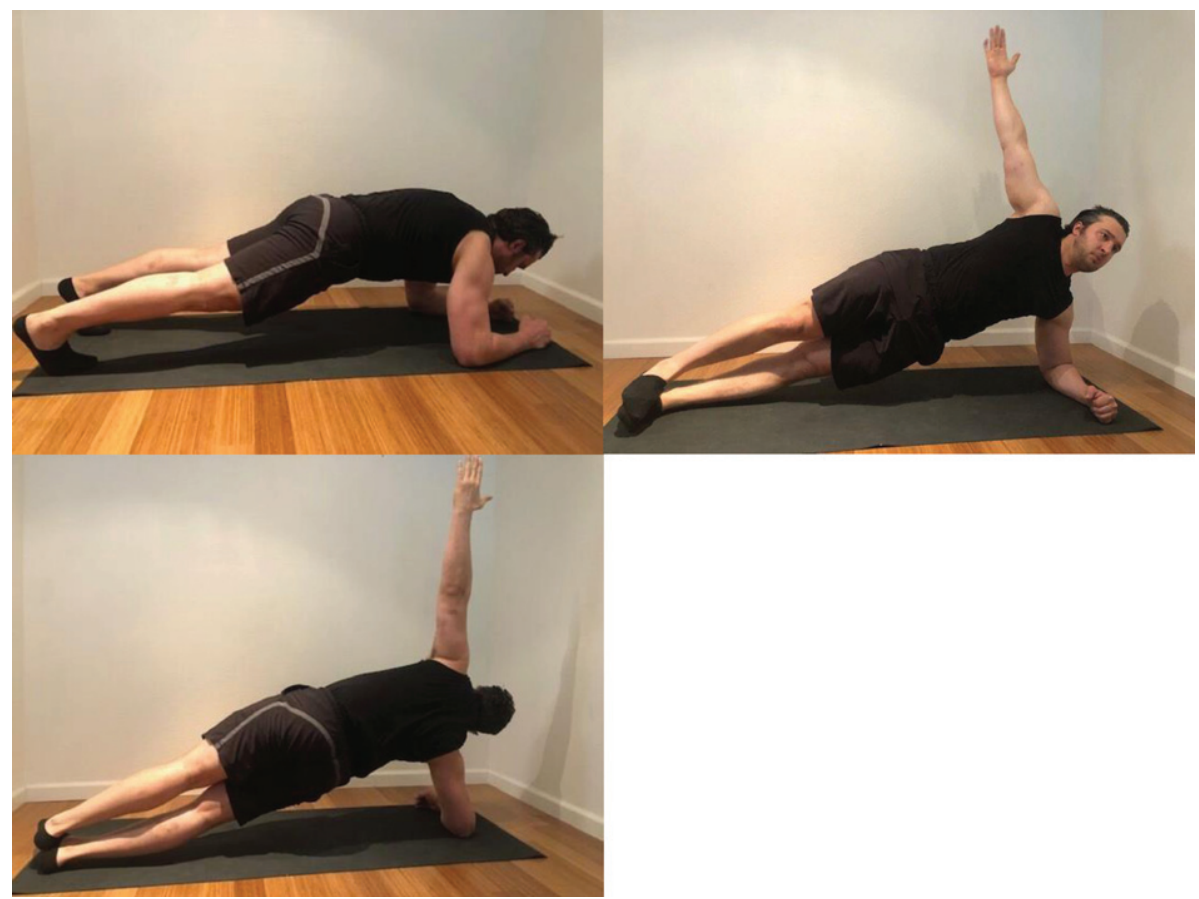

*Photo Credit: Ayushi Agrawal, B.S.

Fig. 1. 
Table 1

Description of at home computer-based workers stretching movements

\begin{tabular}{|c|c|}
\hline No. & Stretching movements \\
\hline 1 & $\begin{array}{l}\text { While sitting on a chair, cross all fingers, and stretch both arms as far as possible above the head, holding the stretch for } \\
10 \text { seconds. }\end{array}$ \\
\hline 2 & $\begin{array}{l}\text { While sitting on a chair, extend the left leg. Next, stretch both arms as far as possible above the head, holding the stretch } \\
\text { for } 10 \text { seconds. Repeat with right leg extended. }\end{array}$ \\
\hline 3 & $\begin{array}{l}\text { While sitting on a chair, place both hands on the armrest. Next, rotate the body } 180 \text { degrees to the left, holding the } \\
\text { stretch for } 10 \text { seconds. Repeat rotating the body to the right. }\end{array}$ \\
\hline 4 & $\begin{array}{l}\text { While sitting on a chair, place the ankle of the left leg on top of the knee of the right leg. Push down with both arms, } \\
\text { holding the stretch for } 10 \text { seconds. Repeat switching legs. }\end{array}$ \\
\hline 5 & While sitting on a chair, reach both arms horizontally as far as possible, hold the stretch for 10 seconds. \\
\hline 6 & While sitting on a chair, lift the left leg horizontally as far as possible. Hold for 10 seconds. Repeat with the right leg. \\
\hline 7 & $\begin{array}{l}\text { While standing, place both hands on the back of the chair. Bend your back to stretch the hamstring muscles. Hold stretch } \\
\text { for } 10 \text { seconds. }\end{array}$ \\
\hline 8 & $\begin{array}{l}\text { Repeat stretch } 7 \text {, while alternatively moving your hands to the left side of the chair and to the right side of the chair, } \\
\text { holding for } 10 \text { seconds each. }\end{array}$ \\
\hline 9 & $\begin{array}{l}\text { While standing, place both hands on the back of the chair. Extend the left leg back until straight. Rotate the body } 90 \\
\text { degrees, such that the left elbow is touching the right knee. Repeat switching sides and holding each stretch for } 10 \\
\text { seconds. }\end{array}$ \\
\hline 10 & Repeat movement 6 , but while standing instead of sitting. Hold the stretch for 10 seconds. Repeat with the other leg. \\
\hline 11 & While standing, place both hands on the back of the chair. Squat to 90 degrees, and repeat the movement 10 times. \\
\hline 12 & Repeat movement 3 , but while standing instead of sitting. Hold the stretch for 10 seconds. Repeat with the other leg. \\
\hline
\end{tabular}

byproduct must then be cleared by the pulmonary system, leading to increased cardiovascular output $[34,35]$. Thus, strength training can be effective in developing the cardiovascular system in addition to strict "cardio".

\subsection{Exercise frequency, intensity, time and type (FITT)}

All exercises can be accomplished with minimal equipment (just a couple of pieces of office or household furniture). Three levels of exercise progression and difficulty for use based on your fitness level are provided as well. Confirm that you are physically fit enough to complete these movements before you start and consult your Physician. Do not participate in any of these movements if you have any uncertainty about your safety in performing movements.

General guidelines for the exercises (except for prone row and core movements):

1 - Figure 1 represent three levels of movement difficulty increasing sequentially as well as the starting point (maximum eccentric position) and middle point (maximum point of contraction).

2 - During each movement, ensure that your glute muscles and core are engaged to maintain a braced neutral position throughout the movement.
3 - Use either a 3:1 or 2:1 seconds ratio for the eccentric movement portion to concentric movement portion.

4 - Sets and repetitions: aim for 3-5 sets comprised of $1-15$ repetitions and rest as needed between sets.

5 - All movements can be completed with minimal equipment that can be found in an office and home environment: wall, door frame, table, or chair.

\section{Stretching training}

Stretching is beneficial to prevent stiffness of the joints and muscles. A sedentary lifestyle associated with the quarantine can potentially result in decreased flexibility which is vital to maintaining overall fitness and posture [36, 37]. Additionally, stretching can assist with providing nutrients to soft tissues and ligaments. Decreased stretching activities can lead to tissues becoming degraded [38].

Studies have reported that stretching exercises can prevent stiffness, but the proper dosage to maximize flexibility has yet to be determined [39]. The currently proposed exercise regimen is novel in that it (1) can be performed in any office/home, (2) no special equipment is needed, (3) the exercises are easy to understand and perform all of which have been 
recommended by the American College of Sports Medicine (ACSM) [38].

\subsection{Exercise frequency, intensity, time and type (FITT)}

The 13 stretching exercises are specifically designed for being performed at home [40]. The exercises should be performed an average of 10-15 minutes in length and three times a week. All exercises consist of 10 repetitions (or last for a period of 10-15 s), and the exercises should be performed three times daily (with a rest of 60-90 s between sets). The exercise should be performed in a slow and controlled fashion. The stretching exercises are performed by putting tension on a muscle typically at the end of the range of motion and should be felt as mild discomfort [38]. It should be noted that these exercises have been modified from Mckenzie and William [41] with the intention of increasing flexibility in a home environment.

\section{Conclusion}

This manuscript proposes a novel multicomponent exercise and stretching regimen that individuals will be able to utilize during the quarantine shutdown in response to COVID-19. We believe this routine will aid in the mitigation of weight gain and will reduce the onset of musculoskeletal pain conditions brought on by a decrease in activity. Additionally, maintenance of physical activity during the COVID-19 shutdown will serve to reduce psychological symptomology and bolster the mental health of the population during a very challenging time.

\section{Conflict of interest}

None to report.

\section{References}

[1] Liu S-L, Saif L. Emerging viruses without borders: The Wuhan coronavirus. Multidisciplinary Digital Publishing Institute. Viruses. 2020;12(2):130-6.

[2] The species Severe acute respiratory syndrome-related coronavirus: classifying 2019-nCoV and naming it SARSCoV-2. Nat Microbiol. 2020;5(4):536-44.

[3] Gralinski LE, Menachery VD. Return of the Coronavirus: 2019-nCoV. Viruses. 2020;12(2):135.
[4] Organization WH. Statement on the second meeting of the International Health Regulations Emergency Committee regarding the outbreak of novel coronavirus (2019-nCoV), Geneva, Switzerland, 30 January 2020.

[5] Roser M, Ritchie H, Ortiz-Ospina E. Coronavirus Disease (COVID-19)-Statistics and Research. Our World in data. 2020;

[6] Wilder-Smith A, Freedman DO. Isolation, quarantine, social distancing and community containment: pivotal role for oldstyle public health measures in the novel coronavirus (2019nCoV) outbreak. J Travel Med. 2020;27(2):taaa020.

[7] Sohrabi C, Alsafi Z, O'Neill N, Khan M, Kerwan A, Al-Jabir A, et al. World Health Organization declares global emergency: A review of the 2019 novel coronavirus (COVID-19). Int J Surg. 2020;76:71-6.

[8] Organization WH. Considerations for quarantine of individuals in the context of containment for coronavirus disease (COVID-19): interim guidance, 19 March 2020. World Health Organization; 2020.

[9] Wang C, Pan R, Wan X, Tan Y, Xu L, Ho CS, et al. Immediate psychological responses and associated factors during the initial stage of the 2019 coronavirus disease (COVID19) epidemic among the general population in China. Int J Environ Res Public Health. 2020;17(5):1729.

[10] Pratt M, Varela AR, Salvo D, Kohl III HW, Ding D. Attacking the pandemic of physical inactivity: what is holding us back? Br J Sports Med; 2019.

[11] Kohl3rd HW, Craig CL, Lambert EV, Inoue S, Alkandari JR, Leetongin G, Kahlmeier S, Group LPASW. The pandemic of physical inactivity: global action for public health. Lancet. 2012;380(9838):294-305.

[12] Patterson R, McNamara E, Tainio M, de Sá TH, Smith AD, Sharp SJ, et al. Sedentary behaviour and risk of all-cause, cardiovascular and cancer mortality, and incident type 2 diabetes: a systematic review and dose response meta-analysis. Eur J Epidemiol. 2018;33(9):811-29.

[13] Young DR, Hivert M-F, Alhassan S, Camhi SM, Ferguson JF, Katzmarzyk PT, et al. Sedentary behavior and cardiovascular morbidity and mortality: a science advisory from the American Heart Association. Circulation. 2016;134(13):e262-79.

[14] Chow N, Fleming-Dutra K, Gierke R, Hall A, Hughes M, Pilishvili T, Ritchey M. Preliminary Estimates of the Prevalence of Selected Underlying Health Conditions Among Patients with Coronavirus Disease 2019-United States, February 12-March 28, 2020. MMWR Morb Mortal Wkly Rep. 2020;69(13):382.

[15] Shariat A, Cardoso JR, Cleland JA, Danaee M, Ansari NN, Kargarfard M, et al. Prevalence rate of neck, shoulder and lower back pain in association with age, body mass index and gender among Malaysian office workers. Work. 2018;60(2):1-9.

[16] Shariat A, Tamrin SBM, Arumugam M, Danaee M, Ramasamy R. Office exercise training to reduce and prevent the occurrence of musculoskeletal disorders among office workers: a hypothesis. Malays J Med Sci. 2016;23(4):54.

[17] Shariat A. Musculoskeletal disorders and their relationship with physical activities among office workers: a review. Malaysia J Pub Heal Med. 2016;16(1):62-74.

[18] Shariat A, Tamrin SBM, Danaee M. Absence of physical exercise and incidence of musculoskeletal discomforts among office workers: a short review. Malay J Hum Fac Ergo. 2017;1(2):16-21.

[19] Qin F, Song Y, Nassis GP, Zhao L, Cui S, Lai L, et al. Prevalence of Insufficient Physical Activity, Sedentary Screen 
Time and Emotional Well-Being During the Early Days of the 2019 Novel Coronavirus (COVID-19) Outbreak in China: A National Cross-Sectional Study. 2020;

[20] Alizadeh R, Shariat A, Ansari NN, Kordi R, Cleland JA, Hakakzadeh A, et al. Office-based Exercise Therapy as a Non-pharmacological Treatment for Discogenic Low Back Pain among Army Staff. Iran J Public Health. 2018;47(12):1969-70.

[21] Cadore EL, de Asteasu MLS, Izquierdo M. Multicomponent exercise and the hallmarks of frailty: Considerations on cognitive impairment and acute hospitalization. Exp Gerontol. 2019;122:10-14.

[22] Caspersen CJ, Powell KE, Christenson GM. Physical activity, exercise, and physical fitness: definitions and distinctions for health-related research. Public Health Rep. 1985;100(2):126-31.

[23] Services USD of H and H. US Department of Health and Human Services 2008 physical activity guidelines for Americans. Hyattsville, MD: Author. 2008;

[24] Garber CE, Blissmer B, Deschenes MR, Franklin BA, Lamonte MJ, Lee I-M, et al. Quantity and quality of exercise for developing and maintaining cardiorespiratory, musculoskeletal, and neuromotor fitness in apparently healthy adults: guidance for prescribing exercise. Med Sci Sports Exerc. 2011;43(7):1334-59.

[25] Haskell WL, Lee I-M, Pate RR, Powell KE, Blair SN, Franklin BA, et al. Physical activity and public health: updated recommendation for adults from the American College of Sports Medicine and the American Heart Association. Med Sci Sports Exerc. 2007;39(8):1423-34.

[26] Nelson ME, Rejeski WJ, Blair SN, Duncan PW, Judge JO, King AC, et al. Physical activity and public health in older adults: recommendation from the American College of Sports Medicine and the American Heart Association. Med Sci Sports Exerc. 2007;39(8):1435-45.

[27] Sisson SB, Katzmarzyk PT, Earnest CP, Bouchard C, Blair SN, Church TS. Volume of exercise and fitness nonresponse in sedentary, post-menopausal women. Med Sci Sports Exerc. 2009;41(3):539.

[28] Swain DP, Franklin BA. VO2 reserve and the minimal intensity for improving cardiorespiratory fitness. Med Sci Sports Exerc. 2002;34(1):152-7.

[29] Swain DP, Leutholtz BC. Heart rate reserve is equivalent to\% VO2Reserve, not to\% VO2max. Med Sci Sports Exerc. 1997;29(3):410-4.
[30] González K, Fuentes J, Márquez JL. Physical inactivity, sedentary behavior and chronic diseases. Korean J Fam Med. 2017;38(3):111.

[31] Figueiró TH, Arins GCB, dos Santos CES, Cembranel F, de Medeiros PA, d'Orsi E, et al. Association of objectively measured sedentary behavior and physical activity with cardiometabolic risk markers in older adults. PloS one. 2019;14(1).

[32] Hulteen RM, Morgan PJ, Barnett LM, Stodden DF, Lubans DR. Development of foundational movement skills: A conceptual model for physical activity across the lifespan. Sports Med. 2018;48(7):1533-40.

[33] Nieman DC, Wentz LM. The compelling link between physical activity and the body's defense system. J Sport Health Sci. 2019;8(3):201-17.

[34] Artero EG, Lee D, Lavie CJ, España-Romero V, Sui X, Church TS, et al. Effects of muscular strength on cardiovascular risk factors and prognosis. J Cardiopulm Rehabil Prev. 2012;32(6):351.

[35] Mcleod JC, Stokes T, Phillips SM. Resistance exercise training as a primary countermeasure to age-related chronic disease. Front Physiol. 2019;10:645.

[36] Jussila L, Paananen M, Näyhä S, Taimela S, Tammelin $\mathrm{T}$, Auvinen J, et al. Psychosocial and lifestyle correlates of musculoskeletal pain patterns in adolescence: A 2-year follow-up study. Eur J Pain. 2014;18(1):139-46.

[37] Teo PS, Abdullah N-F, Chen CK, Aziz ME, Foo LH. High sedentary lifestyle practices has adverse influence on musculoskeletal health in adolescent boys and girls: findings from a population-based study in Malaysia. In: 6th International Conference on Children. BioScientifica; 2013.

[38] Medicine AC of S. ACSM's guidelines for exercise testing and prescription. Lippincott Williams \& Wilkins; 2013.

[39] Coggon D, Ntani G, Palmer KT, Felli VE, Harari R, Barrero $\mathrm{LH}$, et al. Disabling musculoskeletal pain in working populations: Is it the job, the person, or the culture? Pain. 2013;154(6):856-63.

[40] Shariat A, Lam ETC, Kargarfard M, Tamrin SBM, Danaee $\mathrm{M}$. The application of a feasible exercise training program in the office setting. Work. 2017;56(3).

[41] Hosseinifar M, Akbari M, Behtash H, Amiri M, Sarrafzadeh J. The effects of stabilization and McKenzie exercises on transverse abdominis and multifidus muscle thickness, pain, and disability: a randomized controlled trial in nonspecific chronic low back pain. J Phys Ther Sci. 2013;25(12):1541-5. 